\title{
Donor milk: current perspectives
}

This article was published in the following Dove Press journal:

Research and Reports in Neonatology

14 July 2014

Number of times this article has been viewed

Francesca Giuliani'

Ilaria Rovelli'

Chiara Peila'

Stefania Alfonsina Liguori ${ }^{2}$

Enrico Bertino'

Alessandra Coscia'

'SCDU Neonatologia, Dipartimento di Scienze Pediatriche e

dell’Adolescenza, Università degli

Studi di Torino, Torino, Italy; ${ }^{2} \mathrm{SC}$

Neonatologia, Ospedale Maria

Vittoria, Torino, Italy
Correspondence: Francesca Giuliani SCDU Neonatologia, Via Ventimiglia,

3 - I0I3| Torino, Italy

Tel +393339075767

Email giuliani.pediatria@gmail.com
Abstract: Mother's own milk is widely recognized as the optimal feeding for term infants, but increasing evidence exists of its benefits also for sick and preterm infants in neonatal intensive care units. However, the nutritional needs for appropriate growth and neurodevelopmental outcomes of such a particular population of infants should be attentively evaluated, considering also the indication to an appropriate fortification of human milk. The target is to achieve growth potential for preterm newborns while ensuring good metabolic outcomes and normal neurological development. When mother's milk is unavailable or in short supply, donor human milk (DHM) represents the second best choice and, although somewhat modified by the Holder pasteurization process, it preserves many benefits when compared to formula, as documented by more and more reports, randomized controlled trials, and meta-analyses published in the past few years. Evidence exists of the protection exerted by DHM from necrotizing enterocolitis, while further studies are required to look at possible beneficial effects regarding infections, bronchopulmonary dysplasia, long-term cardiovascular risk factors, feeding tolerance, neurological outcome, and allergy. Finally, the concern that the use of DHM might decrease preterm infant breastfeeding is being raised. Conversely, publications exist showing that the use of DHM in the neonatal unit increases breastfeeding rates at discharge for infants of very low birth weight.

Keywords: human milk, preterm infant feeding, milk bank, breast milk, mother's own milk, pasteurized human milk, fortification

\section{Background}

Breastfeeding is universally accepted as the normative standard for the feeding and nutrition of infants born at term until 6 months of age, followed by complementary feeding and continued, if possible, well beyond 1 year of life. ${ }^{1}$ During the past decades, increasing evidence confirmed that there are important benefits to the use of maternal milk (MM) for sick and preterm infants in neonatal intensive care units (NICUs). However, the nutritional needs for an appropriate growth and neurodevelopmental outcome of such a particular population of infants should be attentively evaluated, considering also the indication to fortification of human milk. ${ }^{2}$

Feeding MM to preterm infants decreases, when compared to formula, rates of sepsis, necrotizing enterocolitis (NEC), and mortality, while improving neurocognitive and cardiovascular outcomes in the long-term. MM is the first choice for all neonates including preterm infants, and, when it is not available or not sufficient, despite significant lactation support, donor human milk (DHM) is the best choice. ${ }^{1,3,4}$

Besides its use in preterm infant feeding, DHM has been utilized in a variety of clinical conditions such as post-operative realimentation following intestinal resection, severe food allergies, metabolic diseases, immune deficiencies, chronic renal 
insufficiency, and cardiopathies with failure to thrive due to feeding intolerance..$^{5-8}$

This paper aims to present and discuss the published evidence regarding the benefits derived from the use of DHM for preterm infants, with a comment on the main concerns and challenges limiting a wider use.

\section{Biological aspects}

Human milk can be considered a species-specific biological "dynamic" system. In particular, it contains many factors with specific biological roles, such as hormones, growth factors, enzymes, immunoglobulins, lactoferrin, lysozyme, oligosaccharides, nucleotides, antioxidants, and cellular components that possess both an active role in protecting the infant against infections, but also exert an immunomodulant action and select a beneficial intestinal bacterial flora. ${ }^{9-11}$

DHM undergoes the process of pasteurization, with Holder pasteurization being the most commonly used technique. Pasteurization aims at guaranteeing microbiological safety of the product but it partially affects both nutritional and immunological characteristics of milk; however, it is a well recognized fact that pasteurized milk maintains at least some of the protective effects of MM. ${ }^{3}$

Among the factors that exert a protective effect, oligosaccharides have a demonstrated and relevant role. Originally they have been described as a prebiotic "bifidus factor" that serves as a metabolic substrate to select a desired intestinal microbiota with beneficial effects for the breast-fed infant. Nowadays, oligosaccharides are recognized to be more than just "food for bugs". Among the direct effects of human milk, oligosaccharides prevent pathogen adhesion to mucosal surfaces and a modulation of epithelial and immune cell response are described, together with the result of a consequent lower rate of infections. ${ }^{12}$ Focusing on DHM, a few years ago our research group studied the effects of Holder pasteurization on the concentration and pattern of oligosaccharides in preterm human milk. Our results indicate that pasteurization does not affect the concentration or pattern of analyzed oligosaccharides. ${ }^{13}$

The effect of pasteurization and frozen storage on the content and bioavailability of other human milk components, such as fat, bile salt-stimulated lipase, and lipoprotein lipase has been investigated in many studies. In summary, pasteurization has been reported to reduce fat and energy content of milk ${ }^{14}$ as well as fat absorption. ${ }^{15}$ Frozen storage at $-20^{\circ} \mathrm{C}$ of pasteurized milk seems to decrease fat, lactose, and the energy content of milk. ${ }^{14}$

In order to minimize the impact on the nutritional and immunological quality of human milk, different pasteurization methods are under investigation. For example, an alternative to Holder pasteurization is the high-temperature short-time pasteurization. A recent study showed a better preservation of bile salt-stimulated lipase, lactoferrin, and components of the immune system after this pasteurization compared with Holder pasteurization. ${ }^{16}$ However, further studies are recommended to investigate the microbiological safety of alternative pasteurization methods.

\section{Nutritional aspects}

As stated earlier in this paper, MM is universally accepted as the best feeding choice for every infant, mainly for its advantageous nutritional and immunological characteristics. For preterm infants, however, it is suggested that in order to meet their increased nutritional requirements, while maintaining the unique benefit of breastfeeding, MM needs to be appropriately fortified, mainly to guarantee adequate growth and bone mineralization. ${ }^{17}$ Two Cochrane reviews exist reporting better short-term outcomes in terms of weight, linear and head growth for infants whose milk was enriched with a multicomponent fortifier. ${ }^{18,19}$ Even if long-term outcomes are not yet deeply investigated, we should not expect further studies evaluating fortification of human milk versus no supplementation to be performed. On the contrary, further research is needed to compare different fortifiers in order to achieve a composition proven to obtain the best results in short and long-term outcomes. Besides fortifier composition, the best method to tailor it to the preterm infant is still debated; currently, different protocols are used in the neonatal units. If fortified in a standard manner, in half the cases MM fails to meet the protein recommended intake for premature neonates ${ }^{20}$ and an insufficient protein intake is the main factor associated with growth failure in preterm infants.

In the case of DHM, which is usually donated by the mothers of term infants beyond 1 month postpartum, and which is likely to have lower protein content than preterm $\mathrm{MM},{ }^{21-24}$ the issue is even more relevant.

Individual fortification has recently been reported as an effective means to resolve the issue of the variability of expressed DHM composition, mainly regarding its protein and fat content. Fortification can be individualized in two ways: the first is the "adjustable fortification" that takes into account the metabolic response of the infant. The second is the "targeted fortification" that is based on the biochemical analysis of milk, then tailoring the fortification to ensure that each infant always gets the correct nutrient amount. ${ }^{25}$

Moreover, according to Quigley et al, there is a need for further research to investigate the effects of formula feeding 
versus fortified DHM feeding; comparisons of formula versus DHM used as supplements to insufficient MM would also be useful. ${ }^{26}$

\section{Clinical aspects}

The most important clinical aspects are summarized in Table 1, and detailed in the following paragraphs.

\section{NEC}

NEC is one of the most important causes of mortality and morbidity in preterm infants. Even if individual studies have not been able to demonstrate a protective effect of human milk towards NEC, three meta-analyses show a reduction in NEC incidence in neonates fed DHM versus formula. ${ }^{26-28}$ Almost no studies compare the effect of fortified DHM versus formula feeding on NEC incidence.

\section{Infections}

Many studies exist investigating the effects of human milk use on infection incidence, but mainly focus on MM or mixed MM and DHM. In 2004, de Silva et al published a systematic review including three randomized controlled trials (RCTs) and six observational studies regarding the relationship between nutrition, infection, and human milk in preterm very low birth weight infants. Included studies presented methodological flaws, but reviewers could conclude that human milk, when compared with formula, exerts a protective effect towards infections. ${ }^{29}$ The following year, Rønnestad et al published a large prospective study conducted on a population of extremely low birth weight or extremely premature ( $<28$ weeks of gestational age) infants, for whom early enteral feeding with human milk proved to be beneficial, reducing significantly the risk of late-onset sepsis..$^{30}$ Finally, in 2012, Corpeleijn et al published results showing that early (first 10 days of life) nutrition with human milk (MM and/ or DHM) versus formula decreases the risk of NEC, sepsis and/or death during the first 2 months of life. ${ }^{31}$ However, none of these studies addresses specifically the use of DHM as an exclusive diet.

\section{Bronchopulmonary dysplasia}

A reduction in the incidence of bronchopulmonary dysplasia has been observed in one RCT, ${ }^{32}$ but further studies are needed to confirm the observation.

\section{Long-term cardiovascular risk factors}

There is accumulating evidence of lower rates of metabolic syndrome and, in adolescence, lower blood pressures, minor low-density lipoprotein concentrations as well as a lower risk of insulin resistance while examining the long-term outcomes of preterm infants fed MM and/or DHM. ${ }^{33-35}$ However, the significance of these observations is uncertain, mainly due

Table I Effects of DHM versus formula on clinical outcomes

\begin{tabular}{|c|c|c|c|}
\hline Clinical outcomes & Reference & Evidence & New perspectives \\
\hline NEC & $\begin{array}{l}\text { Three systematic reviews } \\
\text { - Boyd et } \mathrm{al}^{27}(2007) \\
\text { - Quigley et } \mathrm{al}^{26} \text { (2007) } \\
\text { - McGuire and Anthony }{ }^{28}(2003)\end{array}$ & $\begin{array}{l}\text { DHM has a protective effect } \\
\text { in premature infants versus } \\
\text { formula }\end{array}$ & $\begin{array}{l}\text { Studies comparing } \\
\text { fortified DHM with } \\
\text { preterm formula }\end{array}$ \\
\hline Infections & $\begin{array}{l}\text { One systematic review } \\
\text { - de Silva et } \text { al }^{29}(2004) \\
\text { Observational studies }\end{array}$ & $\begin{array}{l}\text { DHM not investigated as a sole } \\
\text { diet }\end{array}$ & $\begin{array}{l}\text { Studies with DHM } \\
\text { used as a sole diet }\end{array}$ \\
\hline BPD & $\begin{array}{l}\text { One RCT } \\
\text { - Schanler et } \mathrm{al}^{32}(2005)\end{array}$ & DHM may be protective & Need for more RCTs \\
\hline $\begin{array}{l}\text { Long-term cardiovascular } \\
\text { outcome }\end{array}$ & $\begin{array}{l}\text { Three RCTs } \\
\text { - Lucas et } \mathrm{al}^{33}(1984) \\
\text { - Singhal et } \mathrm{al}^{34}(200 \mathrm{l}) \\
\text { - Singhal et } \mathrm{al}^{35}(2004)\end{array}$ & $\begin{array}{l}\text { DHM may be protective during } \\
\text { adolescence }\end{array}$ & $\begin{array}{l}\text { Studies comparing } \\
\text { fortified DHM versus } \\
\text { preterm formula }\end{array}$ \\
\hline Feeding tolerance & $\begin{array}{l}\text { Two systematic reviews } \\
\text { - Boyd et } \mathrm{al}^{27}(2007) \\
\text { - McGuire and Anthony }{ }^{28}(2003)\end{array}$ & $\begin{array}{l}\text { DHM compared to formula } \\
\text { improves feeding tolerance } \\
\text { (limited data) }\end{array}$ & $\begin{array}{l}\text { Studies comparing } \\
\text { fortified DHM versus } \\
\text { preterm formula }\end{array}$ \\
\hline $\begin{array}{l}\text { Neurodevelopmental } \\
\text { outcome }\end{array}$ & $\begin{array}{l}\text { One RCT } \\
\text { - Lucas et al }{ }^{44}(1994)\end{array}$ & $\begin{array}{l}\text { No beneficial effect of the } \\
\text { unfortified DHM versus } \\
\text { preterm formula }\end{array}$ & $\begin{array}{l}\text { Studies comparing } \\
\text { fortified DHM versus } \\
\text { preterm formula }\end{array}$ \\
\hline Allergy & $\begin{array}{l}\text { One RCT } \\
\text { - Lucas et } \mathrm{al}^{46}(1990)\end{array}$ & $\begin{array}{l}\text { DHM has protective effects } \\
\text { only against eczema in preterms } \\
\text { at high risk for allergy }\end{array}$ & Need of more RCTs \\
\hline
\end{tabular}

Abbreviations: BPD, bronchopulmonary dysplasia; DHM, donor human milk; NEC, necrotizing enterocolitis; RCTs, randomized controlled trials. 
to the fact that the cited studies compare unfortified DHM with formula, while now the common practice is to fortify DHM.

\section{Feeding tolerance}

Only a few experimental studies have been conducted about MM and feeding tolerance. The meta-analysis by Henderson et al found insufficient results from RCTs to be conclusive, ${ }^{36}$ and this is likely to be mainly due to the ethical concerns raised by the randomization of preterm infants to formula or MM, given the demonstrated benefits of the latest results.

Compared to DHM, formula seems to bring more episodes of feed intolerance in preterm infants. ${ }^{27,28}$

There are several observational studies describing a better feeding tolerance and a faster attainment of full enteral feeding when human milk is chosen as a sole diet. In 2012, the results of an international survey about feeding practices in very low birth weight infants were published. Authors state that the unavailability of both MM or DHM plays an important role in the delayed establishment of enteral feeding (55\%-89\% of cases). The reported great variability in feeding practices within the units and the geographical regions was also explained, at least partially, by the different accessibility to DHM. For example, where DHM was available, enteral feeding was more often commenced on the first day of life, even for the most premature newborns, because they did not have to wait for expressed MM to become available. ${ }^{37}$ All these data support the beneficial effects of DHM in enhancing feeding tolerance.

\section{Neurodevelopmental outcome}

The neurodevelopmental outcome of preterm infants is improved by feeding with MM. Long-term studies describing results of follow-up at 8 years of age and until adolescence suggest better results achieved in intelligence tests, and also greater white matter and total brain volumes in preterm infants who had been fed MM during hospital stay. ${ }^{38,39}$

These results are confirmed for extremely preterm infants fed human milk, while in the NICU, studies report significantly better results in mental and motor assessments at 18 months and 30 months of age. The results are still significant after correcting for such factors as maternal education, age, marital status, race, and infant morbidities. ${ }^{40,41}$

The slower growth rate observed in very low birth weight infants fed fortified human milk does not affect the better neurodevelopmental and motor outcomes achieved during the first year of corrected age, ${ }^{42}$ thus shifting the attention from a quantitative to a qualitative evaluation of the growth obtained with human milk compared to formula in preterm infants. This observation had already been highlighted by Lucas et al in their trial, in which no differences in neurological achievements were reported in infants fed preterm formula versus human milk, despite faster growth in the former group. ${ }^{43}$

Focusing on DHM as a sole diet, only one RCT exists and reports no beneficial effect of unfortified DHM versus formula on neurodevelopmental outcome. ${ }^{44}$ There is a need to further investigate the potential effects of fortified DHM.

\section{Allergy}

The neonatal period is a critical window for immunological adaptation, and enteral feeding plays an important role in the development of the immune system through its immunoactive factors. ${ }^{45}$ Only one RCT exists studying the effect of DHM on the allergy risk, reporting no protective effect of DHM on the development of allergy later in life, even if a protective effect of DHM against eczema in preterm infants at high risk for allergy was noted. ${ }^{46}$

\section{Human milk banks}

Growing clinical evidence has placed human milk feeding and the supply of DHM as a basic right for preterm infants. DHM banking should be promoted, protected, and supported as an extension of national breastfeeding policies. ${ }^{3}$

In fact, DHM banks, besides the activities of collecting, processing, and storing DHM, are also a tool for breastfeeding promotion and support. In Italy, data from the Italian Neonatal Network show that in NICUs, exclusive breastfeeding at discharge is achieved for nearly $30 \%$ of neonates when DHM is available during hospital stay and for only $16 \%$ of neonates when it is not. ${ }^{47,48}$

One of the goals of pediatric health care givers is the protection, promotion, and support of breastfeeding. Health care workers should therefore get a good knowledge of the most common breastfeeding issues, should be trained in counseling. and encourage practices that do not undermine breastfeeding. These aspects are even more important for the preterm infants admitted to the NICUs.

Unsuccessful breast milk feeding is a major problem for preterm infants, both in terms of health and costs. Promoting breastfeeding effectively represents a major contribution to improve vulnerable infants health. ${ }^{49}$

\section{Concerns and challenges in the use of DHM}

A more widespread use of DHM is limited by a few concerns and challenges not easy to overcome. 
One of the major concerns is the safety of the milk, which should be screened, collected, processed, stored, and distributed by milk banks operating according to specific guidelines, but unfortunately this is not the rule.

Also, pasteurization, and less importantly, handling and storage, partially affect the nutritional components of human milk, diminishing quantity and/or altering quality and the function of many bioactive or nutritional compounds such as lactoferrin, IgA, lipase, lysozyme, fat, and others. Pasteurization methods other than Holder are currently under investigation, with the aim of a better preservation of the milk quality while not compromising the microbiological safety.

The slower growth of infants fed MM or DHM compared to those fed formula is also of some concern, even if the new fortification strategies may help to achieve better growth rates.

Finally, the use of DHM requires a preliminary analysis of costs and an evaluation of acceptability. In particular, we need to explore different cultural, religious, and social attitudes to DHM. ${ }^{50,51}$ For example, in the Muslim world, the use of DHM is not common in its conventional form. In the western world, the anonymity of the donor milk providers and the pooling of milk often prevents Muslims from accepting donor milk for their infants. The understanding of this issue and providing a rationale for accepting DHM may improve the rate of acceptance among Muslim families. ${ }^{52}$

\section{Conclusion}

So far, the ideal model of postnatal growth of preterm infants has not been described or defined. What is clear already is the paramount importance of nutrition in early life, not only to meet immediate nutritional needs, but also for its potentially long-lasting or life-long biological effects (the term "programming" has been proposed to describe this aspect). ${ }^{17}$ The target is to achieve growth potential for very low birth weight infants and to ensure their good health and normal neurological development. However, we do not yet know what is the most suitable "path" we should follow.

MM is considered the normative standard for preterm infant feeding, and DHM is the next best choice. Evidence exists of the protection exerted by DHM from NEC, while further studies are required to look at possible beneficial effects regarding feeding tolerance, bronchopulmonary dysplasia, and long-term cardiovascular and neurological outcome. Appropriately produced DHM is safe and also works as an instrument to promote breastfeeding in the NICUs.

\section{Disclosure}

The authors report no conflict of interests in this work.

\section{References}

1. American Academy of Paediatrics. Breastfeeding and use of human milk. Pediatrics. 2012;129:e827-e841.

2. Underwood MA. Human Milk for the Premature Infant. Pediatr Clin NAm. 2013;60(1):189-207.

3. Italian Association of Human Milk Banks Associazione Italiana Banche del Latte Umano Donato (AIBLUD http://www.aiblud.org), Arslanoglu S, Bertino E, Tonetto P, et al. Guidelines for the establishment and operation of a donor human milk bank. J Matern Fetal Neonatal Med. 2010;23(2):1-20.

4. Agostoni C, Buonocore G, Carnielli VP, et al; for the ESPGHAN Committee on Nutrition. Enteral nutrient supply for preterm infants: commentary from the European Society of Paediatric Gastroenterology, Hepatology and Nutrition Committee on Nutrition. J Pediatr Gastroenterol Nutr. 2010;50(1):85-91.

5. Anderson A, Arnold LD. Use of donor breastmilk in the nutrition management of chronic renal failure: three case histories. J Hum Lact.1993;9(4):263-264.

6. Arnold LD. Use of donor human milk in the management of failure to thrive: case histories. J Hum Lact. 1995;11(2):137-140.

7. Arnold LD. Use of donor milk in the treatment of metabolic disorders: glycolytic pathway defects. J Hum Lact. 1995;11(1):51-53.

8. Tully MR, Lockhart-Borman L, Updegrove K. Stories of success: the use of donor milk is increasing in North America. J Hum Lact. 2004;20(1):75-77.

9. Hanson LA, Korotkova M, Telemo E. Breastfeeding, infant formulas, and the immune system. Ann Allergy Asthma Immunol. 2003;90(6):59-63.

10. Picciano MF. Nutrient composition of human milk. Pediatr Clin North Am. 2001;48(1):53-67.

11. Fanaro S, Vigi V. Feeding the term infant: human milk and formula. In: G. Buonocore, R. Bracci, M. Weindling, editors. Neonatology. A Practical Approach to Neonatal Diseases: A Practical Approach to Neonatal Management, Milano: Springer, 2012;290-297.

12. Bode L. Human milk oligosaccharides: every baby needs a sugar mama. Glycobiology. 2012;22(9):1147-1162.

13. Bertino E, Coppa GV, Giuliani F, et al. Effects of Holder pasteurization on human milk oligosaccharides. Int J Immunopathol Pharmacol. 2008;21(2):381-385.

14. García-Lara NR, Vieco DE, De la Cruz-Bértolo J, Lora-Pablos D, Velasco NU, Pallás-Alonso CR. Effect of Holder pasteurization and frozen storage on macronutrients and energy content of breast milk. J Pediatr Gastroenterol Nutr. 2013;57(3):377-382.

15. Andersson Y, Sävman K, Bläckberg L, Hernell O. Pasteurization of mother's own milk reduces fat absorption and growth in preterm infants. Acta Paediatr. 2007;96(10):1445-1449.

16. Baro C, Giribaldi M, Arslanoglu S, et al. Effect of two pasteurization methods on the protein content of human milk. Front Biosci (Elite Ed). 2011;3:818-829.

17. De Curtis M, Rigo J. The nutrition of preterm infants. Early Hum Dev. 2012;88:S5-S7.

18. Kuschel CA, Harding JE. Multicomponent fortified human milk for promoting growth in preterm infants [review]. Cochrane Database Syst Rev. 2004;1:CD000343.

19. McCormick FM, Henderson G, Fahey T, McGuire W. Multinutrient fortification of human breast milk for preterm infants following hospital discharge [review]. Cochrane Database Syst Rev. 2010;7: CD004866.

20. Corvaglia L, Aceti A, Paoletti V, et al. Standard fortification of preterm human milk fails to meet recommended protein intake: Bedside evaluation by Near-Infrared-Reflectance-Analysis. Early Hum Dev. 2010;86(4):237-240. 
21. Vieira AA, Soares FV, Pimenta HP, Abranches AD, Moreira ME. Analysis of the influence of pasteurization, freezing/thawing, and offer processes on human milk's macronutrient concentrations. Early Hum Dev. 2011;87(8):577-580.

22. Wojcik KY, Rechtman DJ, Lee ML, Montoya A, Medo ET. Macronutrient analysis of a nationwide sample of donor breast milk. J Am Diet Assoc. 2009;109(1):137-140.

23. Casadio YS, Williams TM, Lai CT, Olsson SE, Hepworth AR, Hartmann PE. Evaluation of a mid-infrared analyzer for the determination of the macronutrient composition of human milk. J Hum Lact. 2010;26(4):376-383.

24. Michaelsen KF, Skafte L, Badsberg JH, Jørgensen M. Variation in macronutrients in human bank milk: influencing factors and implications for human milk banking. J Pediatr Gastroenterol Nutr. 1990;11(2): 229-239.

25. Arslanoglu S, Moro GE, Ziegler EE, The Wapm Working Group On Nutrition. Optimization of human milk fortification for preterm infants: new concepts and recommendations. J Perinat Med. 2010;38(3): 233-238.

26. Quigley MA, Henderson G, Anthony MY, McGuire W. Formula milk versus donor breast milk for feeding preterm or low birth weight infants [review]. Cochrane Database Syst Rev. 2007;4:CD002971.

27. Boyd CA, Quigley MA, Brocklehurst P. Donor breast milk versus infant formula for preterm infants: systematic review and meta-analysis. Arch Dis Child Fetal Neonatal Ed. 2007;92(3):F169-F175.

28. McGuire W, Anthony MY. Donor human milk versus formula for preventing necrotising enterocolitis in preterm infants: systematic review. Arch Dis Child Fetal Neonatal Ed. 2003;88(1):F11-F14.

29. de Silva A, Jones PW, Spencer SA. Does human milk reduce infection rates in preterm infants? A systematic review. Arch Dis Child Fetal Neonatal Ed. 2004;89(6):F509-F513.

30. Rønnestad A, Abrahamsen TG, Medbø S, et al. Late-onset septicemia in a Norwegian national cohort of extremely premature infants receiving very early full human milk feeding. Pediatrics. 2005;115(3): 269-276.

31. Corpeleijn WE, Kouwenhoven SM, Paap MC, et al. Intake of own mother's milk during the first days of life is associated with decreased morbidity and mortality in very low birth weight infants during the first 60 days of life. Neonatology. 2012;102(4):276-281.

32. Schanler RJ, Lau C, Hurst NM, Smith EO. Randomized trial of donor milk versus preterm formula as substitutes for mother's own milk in the feeding of extremely premature infants. Pediatrics. 2005;116(2):400-406.

33. Lucas A, Gore SM, Cole TJ, et al. Multricentre trial on feeding low birth weight infants: effects on diet on early growth. Arch Dis Child. 1984;59(8):722-730.

34. Singhal A, Cole TJ, Lucas A. Early nutrition in preterm infants and later blood pressure: two cohort after randomized trial. Lancet. 2001;357(9254):413-419.

35. Singhal A, Cole TJ, Fewtrell M, Lucas A. Breastmilk feeding and lipoprotein profile in adolescents born preterm: follow up of a prospective randomised study. Lancet. 2004;363(9421):1571-1578.

36. Henderson G, Anthony MY, McGuire W. Formula milk versus maternal breast milk for feeding preterm or low birth weight infants [review]. Cochrane Database Syst Rev. 2007;(4):CD002972.
37. Klingenberg C, Embleton ND, Jacobs SE, O'Connell LA, Kuschel CA. Enteral feeding practices in very preterm infants: an international survey. Arch Dis Child Fetal Neonatal Ed. 2012;97(1): F56-F61.

38. Smith MM, Durkin M, Hinton VJ, Bellinger D, Kuhn L. Influence of breastfeeding on cognitive outcomes at age 6-8 years: follow-up of very low birth weight infants. Am J Epidemiol. 2003;158(11): 1075-1082.

39. Horwood LJ, Darlow BA, Mogridge N. Breast milk feeding and cognitive ability at 7-8 years. Arch Dis Child Fetal Neonatal Ed. 2001;84(1):F23-F27.

40. Vohr BR, Poindexter BB, Dusick AM, et al. Beneficial effects of breast milk in the neonatal intensive care unit on the developmental outcome of extremely low birth weight infants at 18 months of age. Pediatrics. 2006;118(1):e115-e123.

41. Vohr BR, Poindexter BB, Dusick AM, et al. Persistent beneficial effects of breast milk ingested in the neonatal intensive care unit on outcomes of extremely low birth weight infants at 30 months of age. Pediatrics. 2007;120(4):953-959.

42. O'Connor DL, Jacobs J, Hall R, et al. Growth and development of premature infants fed predominantly human milk, predominantly premature infant formula, or a combination of human milk and premature formula. J Pediatr Gastroenterol Nutr. 2003;37(4): 437-446.

43. Lucas A, Morley R, Cole TJ. Randomised trial of early diet in preterm babies and later intelligence quotient. BMJ. 1998;317(7171): 1481-1487.

44. Lucas A, Morley R, Cole TJ, Gore SM. A randomised multicentre study of human milk versus formula and later development in preterm infants. Arch Dis Child Fetal Neonatal Ed. 1994;70(2):F141-F146.

45. ESPGHAN Committee on Nutrition, Arslanoglu S, Corpeleijn W, et al. Donor human milk for preterm infants: current evidence and research directions. J Pediatr Gastroenterol Nutr. 2013;57(4):535-542.

46. Lucas A, Brooke OG, Morley R, Cole TJ, Bamford MF. Early diet of preterm infants and development of allergic or atopic disease: a randomised prospective study. BMJ. 1990;300(6728):837-840.

47. Bertino E, Giuliani F, Baricco M, et al. Benefits of donor milk in the feeding of preterm infants. Early Human Development. 2013;89(2): s3-s6.

48. Arslanoglu S, Moro GE, Bellù R, et al. Presence of human milk bank is associated with elevated rate of exclusive breastfeeding in VLBW infants. J Perinat Med. 2013;41(2):129-131.

49. Renfrew MJ, Dyson L, McCormick F, et al. Breastfeeding promotion for infants in neonatal units: a systematic review. Child: Care Health Dev. 2010;36(2):165-178.

50. Modi N. Donor breast milk banking. BMJ. 2006;333(7579): 1133-1134.

51. McGuire W. Donor human milk for preterm infants. Pediatrics. 2012;130:e462.

52. El-Khuffash A, Unger S. The concept of milk kinship in Islam: issues raised when offering preterm infants of Muslim families donor human milk. J Hum Lact. 2012;28(2):125-127.
Research and Reports in Neonatology

\section{Publish your work in this journal}

Research and Reports in Neonatology is an international, peer-reviewed, open access journal publishing original research, reports, editorials, reviews and commentaries on neonatal health. The manuscript management system is completely online and includes a very quick and fair
Dovepress

peer-review system. Visit http://www.dovepress.com/testimonials.php to read real quotes from published authors. 